\section{(6) OPEN ACCESS}

\title{
Female sex workers incarcerated in New York City jails: prevalence of sexually transmitted infections and associated risk behaviors
}

\author{
Farah Parvez, ${ }^{1,2}$ Monica Katyal, ${ }^{1}$ Howard Alper, ${ }^{1}$ Ruth Leibowitz, ${ }^{3}$ Homer Venters ${ }^{1}$
}

\begin{abstract}
${ }^{1}$ Correctional Health Services, New York City Department of Health and Mental Hygiene, Long Island City, New York, USA

${ }^{2}$ The National Center for HIVI AIDS, Viral Hepatitis, STD, and TB Prevention, Centers for Disease Control and Prevention, Atlanta, Georgia, USA

${ }^{3}$ Information Technology Initiatives, New York City Department of Health and Mental Hygiene, Long Island City, New York, USA
\end{abstract}

Correspondence to Dr Homer Venters, Bureau of Correctional Health Services, New York City Department of Health and Mental Hygiene, 42-09 28th Street, 10th Floor, 10-84, CN-52, Long Island City, NY 11101-4132, USA; hventer1@health.nyc.gov

Received 14 December 2012 Revised 9 April 2013 Accepted 13 April 2013

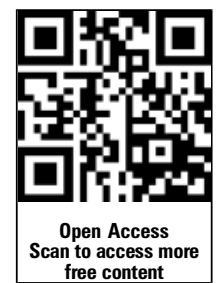

To cite: Parvez F, Katyal M, Alper $\mathrm{H}$, et al. Sex Transm Infect 2013;89:280-284.

\begin{abstract}
Objectives Sexually transmitted infections (STIS) are an important cause of morbidity among incarcerated women and female sex workers (FSW). Little is known about FSW incarcerated in New York City (NYC) jails. We reviewed jail health records to identify the STI and HIV prevalence among newly incarcerated FSW in NYC jails. We also examined the relationship of demographics and self-reported clinical and risk behaviour history with FSW status and compared FSW with non-FSW incarcerated women to identify FSW predictors and, guide NYC jail programme planning and policy.

Methods We retrospectively reviewed routinely collected jail health record data to identify the prevalence of chlamydia $(\mathrm{Ct})$, gonorrhoea $(\mathrm{Ng})$ and HIV infection among women newly incarcerated in NYC jails in 2009-2010 (study period) and studied the relationship of STIS, demographics and self-reported clinical and risk behaviour history with FSW status.

Results During the study period, 10828 women were newly incarcerated in NYC jails. Of these, 10115 (93\%) women were tested for $\mathrm{Ct}$ and $\mathrm{Ng}$; positivity was $6.2 \%$ (95\% Cl $5.7 \%$ to $6.7 \%)$ and $1.7 \%(95 \% \mathrm{Cl} 1.4 \%$ to $1.9 \%)$, respectively. Nine percent had HIV infection. Seven hundred (6.5\%) were defined as FSW. FSW were

women for STI. Correctional settings with comprehensive screening programmes identify high rates of human immunodeficiency virus (HIV), chlamydia $(\mathrm{Ct})$ and gonorrhoea $(\mathrm{Ng})$ infection among women. ${ }^{6}$ As such, STI and HIV testing, treatment and prevention efforts are public health priorities for correctional settings and public health agencies.

Little is known about STI and HIV infection among FSW incarcerated in New York City (NYC) jails. Identifying FSW in jail is difficult; women may not disclose sex work, and currently, jail clinicians do not specifically inquire about it. Prostitution criminal charge is often the only available, though insufficient, FSW marker; other means to identify FSW are needed. We retrospectively reviewed NYC jail health records of newly incarcerated FSW (identified by prostitution charges) with medical intake examinations during 2009-2010 to identify their STI and HIV positivity. We also examined the relationship of demographics and self-reported clinical and risk behaviour history with FSW status and compared FSW to non-FSW incarcerated women to identify FSW predictors and guide NYC jail programme planning and policy.
\end{abstract} more likely to have Ct (adjusted OR (AOR): 1.55; 95\% Cl 1.17 to 2.05; $p<0.0001$ ) but not $\mathrm{Ng}$ or HIV. FSW were more likely to report age 20-24 years, reside in boroughs other than Manhattan, $\geq 6$ prior incarcerations, $\geq 2$ incarcerations during the study period, condom use with current sex partners, multiple sex partners and current drug use.

Conclusions Women incarcerated in NYC jails had high rates of $\mathrm{Ct}, \mathrm{Ng}$, and HIV infection. FSW were at higher risk for $\mathrm{Ct}$ than non-FSW incarcerated women. These findings are being used to design targeted interventions to identify FSW, provide clinical and preventive services in jail and coordinate care with community partners.

\section{INTRODUCTION}

Sexually transmitted infections (STI) are an important cause of morbidity among incarcerated women and female sex workers (FSW). ${ }^{1-3}$ Incarcerated women, particularly FSW, are at increased risk for STI and often report risk behaviours including unprotected sex, sex for drugs or money or multiple sex partners. ${ }^{2}{ }^{4}$ Inadequate health insurance coverage and access to needed clinical and social services are commonly reported. ${ }^{4}$ Incarceration, thus, provides a unique opportunity to screen high-risk

\section{METHODS}

NYC's jail system is the second largest in the USA, annually receiving $>80000$ new admissions, including $>9000$ women. Facilities are operated by the Department of Correction (DOC); healthcare delivery is overseen by Department of Health and Mental Hygiene (DOHMH). Within $24 \mathrm{~h}$ of jail admission, newly incarcerated women receive a medical history and physical (intake) including routine voluntary rapid HIV testing and urine- or endocervical swab-based $\mathrm{Ct}$ and $\mathrm{Ng}$ screening. Median length of stay (LOS) is 7 days; $\sim 25 \%$ of women are released $\leq 3$ days after admission. $\mathrm{Ct}$ and $\mathrm{Ng}$ test results are available within 3 days, enabling treatment of $>65 \%$ of STI-diagnosed women with appropriate antimicrobials prior to release. During testing, women are educated about DOHMH STI clinics where they may receive test results, treatment and partner notification assistance. HIV-infected women receive treatment if indicated and discharge planning.

Routine jail electronic health record (EHR) data were extracted for newly incarcerated women having $\geq 1$ medical intake from 1 January 2009 to 31 December 2010 (study period) and included demographics, self-reported HIV history, sexual 
Table 1 Factors associated with being a female sex worker among women incarcerated in New York City jails, 2009-2010

\begin{tabular}{|c|c|c|c|c|c|}
\hline & \multirow{2}{*}{$\begin{array}{l}\text { Total } \\
\mathrm{N}\end{array}$} & \multicolumn{2}{|c|}{$\begin{array}{l}\text { Female sex } \\
\text { worker-Yes }\end{array}$} & \multirow{2}{*}{$\begin{array}{l}\text { Univariate logistic regression } \\
\text { OR }(95 \% \mathrm{Cl})\end{array}$} & \multirow{2}{*}{$\begin{array}{l}\text { Multivariate logistic regression } \\
\text { OR }(95 \% \mathrm{Cl})\end{array}$} \\
\hline & & $\mathbf{N}$ & (Row \%) & & \\
\hline TOTAL & 10828 & 700 & (6.5) & & \\
\hline \multicolumn{6}{|l|}{ Demographic/incarceration characteristics } \\
\hline \multicolumn{6}{|l|}{ Age, years* } \\
\hline $16-19$ & 1070 & 69 & (6.4) & $0.96(0.72$ to 1.28$)$ & $1.07(0.77$ to 1.49$)$ \\
\hline $20-24$ & 1689 & 136 & (8.1) & $1.22(0.97$ to 1.53$)$ & 1.42 (1.09 to 1.85$)$ \\
\hline $25-34$ & 2595 & 198 & (7.6) & 1.15 (0.94 to 1.42$)$ & $1.26(1.00$ to 1.58$)$ \\
\hline $35-44$ & 2852 & 191 & (6.7) & Reference & Reference \\
\hline $45-54$ & 2258 & 102 & (4.5) & $0.66(0.52$ to 0.84$)$ & $0.83(0.64$ to 1.08$)$ \\
\hline$\geq 55$ & 354 & 4 & $(1.1)$ & 0.16 (0.06 to 0.43$)$ & $0.33(0.12$ to 0.91$)$ \\
\hline Unknown & 10 & 0 & $(0.0)$ & $<0.01(<0.01$ to $>999.99)$ & $<0.01(<0.01$ to $>999.99)$ \\
\hline \multicolumn{6}{|l|}{ Race/ethnicity* } \\
\hline NH Black & 6406 & 414 & (6.5) & Reference & Reference \\
\hline Hispanic & 2810 & 176 & (6.3) & $0.97(0.81$ to 1.16$)$ & $1.00(0.82$ to 1.23$)$ \\
\hline NH White & 1239 & 85 & (6.7) & 1.07 (0.84 to 1.36$)$ & $0.96(0.73$ to 1.27$)$ \\
\hline NH API/American Indian/Other & 353 & 24 & $(6.8)$ & 1.06 (0.69 to 1.62$)$ & 1.68 (1.06 to 2.66$)$ \\
\hline Unknown & 20 & 1 & $(0.1)$ & 0.76 (0.10 to 5.71$)$ & 0.26 (0.03 to 2.42$)$ \\
\hline \multicolumn{6}{|l|}{ Borough of Residence* } \\
\hline Bronx & 2336 & 144 & $(6.2)$ & 2.57 (1.81 to 3.64$)$ & 2.73 (1.90 to 3.94$)$ \\
\hline Brooklyn & 3415 & 232 & (6.8) & 2.85 (2.04 to 3.98$)$ & 2.47 (1.75 to 3.50$)$ \\
\hline Manhattan & 1683 & 42 & (2.5) & Reference & Reference \\
\hline Queens & 1561 & 141 & $(9.0)$ & 3.88 (2.73 to 5.52$)$ & 4.93 (3.41 to 7.14$)$ \\
\hline Staten Island & 446 & 27 & $(6.1)$ & 2.52 (1.53 to 4.13$)$ & 2.43 (1.44 to 4.11$)$ \\
\hline Other & 1387 & 114 & $(8.2)$ & 3.50 (2.44 to 5.02$)$ & 4.53 (3.03 to 6.76$)$ \\
\hline \multicolumn{6}{|l|}{ Ever homeless during study period } \\
\hline Yes & 791 & 94 & $(11.9)$ & 2.10 (1.67 to 2.64$)$ & $0.70(0.52$ to 0.95$)$ \\
\hline No & 10037 & 606 & $(6.0)$ & Reference & Reference \\
\hline \multicolumn{6}{|l|}{ Marital status* } \\
\hline Single, never married & 8616 & 600 & (7.0) & Reference & Reference \\
\hline Married/Cohabiting & 1617 & 72 & (4.5) & 0.62 (0.49 to 0.80$)$ & $0.73(0.56$ to 0.95$)$ \\
\hline Divorced/Separated & 371 & 15 & $(4.0)$ & 0.56 (0.33 to 0.95$)$ & $0.72(0.41$ to 1.27$)$ \\
\hline Widowed & 158 & 6 & $(3.8)$ & 0.53 (0.23 to 1.20$)$ & 0.94 (0.40 to 2.25$)$ \\
\hline Unknown & 66 & 7 & $(10.6)$ & 1.59 (0.72 to 3.49$)$ & $2.15(0.84$ to 5.52$)$ \\
\hline \multicolumn{6}{|l|}{ Education* } \\
\hline$<$ High school diploma/equivalent & 4960 & 362 & $(7.3)$ & $1.00(0.84$ to 1.19$)$ & $0.98(0.81$ to 1.18$)$ \\
\hline High school diploma/equivalent & 2921 & 214 & (7.3) & Reference & Reference \\
\hline Some college & 1756 & 74 & $(4.2)$ & $0.56(0.42$ to 0.73$)$ & $0.70(0.52$ to 0.93$)$ \\
\hline$\geq$ College degree & 483 & 12 & (2.5) & 0.32 (0.18 to 0.58$)$ & $0.42(0.23$ to 0.79$)$ \\
\hline Unknown & 708 & 38 & (5.4) & 0.72 (0.50 to 1.02$)$ & 0.79 (0.47 to 1.33$)$ \\
\hline \multicolumn{6}{|c|}{ Number of prior incarcerations (in last 3 years) } \\
\hline 0 & 7866 & 427 & (5.4) & Reference & Reference \\
\hline 1 & 1268 & 62 & (4.9) & $0.90(0.68$ to 1.18$)$ & $0.76(0.57$ to 1.01$)$ \\
\hline 2 & 628 & 51 & (8.1) & 1.54 (1.14 to 2.08$)$ & $1.01(0.73$ to 1.41$)$ \\
\hline $3-5$ & 713 & 73 & $(10.2)$ & 1.99 (1.53 to 2.58$)$ & $1.05(0.78$ to 1.40$)$ \\
\hline$\geq 6$ & 353 & 87 & (24.6) & $5.70(4.39$ to 7.40$)$ & 1.81 (1.32 to 2.47$)$ \\
\hline \multicolumn{6}{|c|}{ Number of incarcerations during study period } \\
\hline 1 & 7657 & 263 & (3.4) & Reference & Reference \\
\hline 2 & 1752 & 135 & (7.7) & 2.35 (1.89 to 2.91$)$ & $2.32(1.84$ to 2.93$)$ \\
\hline 3 & 652 & 101 & $(15.5)$ & 5.15 (4.03 to 6.59$)$ & 4.86 (3.66 to 6.45$)$ \\
\hline$\geq 4$ & 767 & 201 & $(26.2)$ & $9.98(8.15$ to 12.23$)$ & 8.61 (6.59 to 11.25$)$ \\
\hline \multicolumn{6}{|l|}{ Current drug use } \\
\hline Yes & 4411 & 403 & (9.1) & 2.07 (1.77 to 2.42 ) & 1.24 (1.02 to 1.50$)$ \\
\hline No & 6417 & 297 & (4.6) & Reference & Reference \\
\hline \multicolumn{6}{|l|}{ Physical assault history } \\
\hline Yes & 2501 & 179 & (7.2) & 1.12 (0.93 to 1.33$)$ & 0.88 (0.69 to 1.11$)$ \\
\hline No & 7641 & 494 & (6.5) & Reference & Reference \\
\hline Unknown & 686 & 27 & (3.9) & 0.59 (0.40 to 0.88$)$ & 1.53 (0.84 to 2.78$)$ \\
\hline
\end{tabular}


Table 1 Continued

\begin{tabular}{|c|c|c|c|c|c|}
\hline & \multirow{2}{*}{$\begin{array}{l}\text { Total } \\
\mathrm{N}\end{array}$} & \multicolumn{2}{|c|}{$\begin{array}{l}\text { Female sex } \\
\text { worker-Yes }\end{array}$} & \multirow{2}{*}{$\begin{array}{l}\text { Univariate logistic regression } \\
\text { OR }(95 \% \mathrm{Cl})\end{array}$} & \multirow{2}{*}{$\begin{array}{l}\text { Multivariate logistic regression } \\
\text { OR }(95 \% \mathrm{CI})\end{array}$} \\
\hline & & $\mathrm{N}$ & (Row \%) & & \\
\hline \multicolumn{6}{|c|}{ Sexual abuse history } \\
\hline Yes & 1890 & 159 & (8.4) & $1.38(1.14$ to 1.66$)$ & 1.00 (0.79 to 1.28$)$ \\
\hline No & 8309 & 520 & (6.4) & Reference & Reference \\
\hline Unknown & 629 & 21 & (3.3) & $0.52(0.33$ to 0.81$)$ & 1.02 (0.49 to 2.11$)$ \\
\hline \multicolumn{6}{|c|}{ Intimate partner violence history } \\
\hline Yes & 1558 & 140 & $(9.0)$ & $1.48(1.22$ to 1.80$)$ & 1.01 (0.79 to 1.29$)$ \\
\hline No & 8585 & 536 & $(6.2)$ & Reference & Reference \\
\hline Unknown & 685 & 24 & (3.5) & $0.55(0.36$ to 0.83$)$ & 1.23 (0.73 to 2.07$)$ \\
\hline \multicolumn{6}{|c|}{ Condom use with current sex partner(s) ${ }^{*}$} \\
\hline Yes & 3330 & 349 & $(10.5)$ & 2.36 (2.01 to 2.77$)$ & 1.76 (1.47 to 2.10$)$ \\
\hline No & 6453 & 305 & $(4.7)$ & Reference & Reference \\
\hline Unknown & 1045 & 46 & $(4.4)$ & 0.93 (0.68 to 1.28$)$ & 1.00 (0.64 to 1.54$)$ \\
\hline \multicolumn{6}{|c|}{ Number of current sex partners* } \\
\hline 0 & 2112 & 75 & (3.6) & Reference & Reference \\
\hline 1 & 6833 & 425 & $(6.2)$ & 1.80 (1.40 to 2.31$)$ & 1.53 (1.17 to 2.00$)$ \\
\hline $2-3$ & 703 & 91 & $(12.9)$ & $4.04(2.94$ to 5.56$)$ & 2.56 (1.80 to 3.63$)$ \\
\hline $4+$ & 284 & 70 & $(24.6)$ & $8.88(6.23$ to 12.67$)$ & 4.57 (3.05 to 6.89$)$ \\
\hline Unknown & 896 & 39 & $(4.3)$ & 1.24 (0.83 to 1.84$)$ & 1.69 (1.01 to 2.83$)$ \\
\hline \multicolumn{6}{|c|}{ Pregnant during study period } \\
\hline Yes & 639 & 66 & $(10.3)$ & 1.71 (1.31 to 2.24$)$ & 1.00 (0.74 to 1.35$)$ \\
\hline No & 9963 & 628 & (6.3) & Reference & Reference \\
\hline Unknown & 226 & 6 & $(2.7)$ & 0.41 (0.18 to 0.92$)$ & 0.91 (0.38 to 2.18 ) \\
\hline \multicolumn{6}{|l|}{ Clinical status } \\
\hline \multicolumn{6}{|c|}{ Ever Chlamydia-positive } \\
\hline Yes & 623 & 85 & (13.6) & 2.34 (1.84 to 2.99$)$ & 1.55 (1.17 to 2.05$)$ \\
\hline No & 9492 & 600 & (6.3) & Reference & Reference \\
\hline Not tested & 713 & 15 & (2.1) & 0.32 (0.19 to 0.54$)$ & N/At \\
\hline \multicolumn{6}{|c|}{ Ever Gonorrhoea-positive } \\
\hline Yes & 167 & 30 & $(18.0)$ & 3.11 (2.08 to 4.65$)$ & 1.46 (0.92 to 2.33$)$ \\
\hline No & 9948 & 655 & (6.6) & Reference & Reference \\
\hline Not tested & 713 & 15 & $(2.1)$ & 0.31 (0.18 to 0.51$)$ & 0.41 (0.22 to 0.78 ) \\
\hline \multicolumn{6}{|l|}{ HIV status } \\
\hline Positive & 975 & 76 & (7.8) & $1.03(0.80$ to 1.33$)$ & $0.95(0.71$ to 1.27$)$ \\
\hline Negative & 6585 & 499 & (7.6) & Reference & Reference \\
\hline Unknown & 3268 & 125 & (3.8) & $0.49(0.40$ to 0.59$)$ & 0.94 (0.76 to 1.18$)$ \\
\hline
\end{tabular}

risk behaviours, current drug use, lifetime physical assault/sexual abuse/intimate partner violence (IPV) history; current pregnancy; and jail $\mathrm{Ct}, \mathrm{Ng}$ and HIV testing (table 1). Demographics (age, race/ethnicity, borough of residence, marital status, education) and sexual risk behaviours (current condom use, number of sex partners) were tabulated from the first incarceration during the study period. Remaining variables were computed across all incarcerations during the study period and counted as 'yes'/positive if ever so in any incarceration. HIV positivity was determined using self-reported history, EHR documentation of infection and jail testing data. $\mathrm{Ct}$ and $\mathrm{Ng}$ positivity with exact binomial 95\% CIs were calculated using jail testing results (no. of unique women testing positive/no. of unique women tested). Women with multiple positive tests were counted once as 'positive'. DOC provided data on self-reported homelessness, LOS, prior NYC jail incarceration ( $\leq 3$ years) and criminal charges. 'Ever homeless' status was assigned by report of homelessness at any incarceration. Cumulative LOS was calculated by summing all incarceration days. FSW were identified by $\geq 1$ prostitution charges (New York Penal Law \$110-230.00,110-
240.37,230.00,240.37) among the top five charges occurring across all incarcerations.

Data were tabulated; $\chi^{2}$-statistics were used to identify factors associated with FSW status. Unadjusted ORs and 95\% CIs were calculated for all variables in table 1 . Variables significant in bivariate analysis $(\mathrm{p}<0.10)$ were analysed using multivariate logistic regression to determine predictors of FSW status; adjusted ORs (AORs) and 95\% CIs were calculated. Variable 'unknown' values were retained to maximise statistical power because some variables had $>500$ unknown observations. Analyses were conducted using SAS V.9.2 (SAS Institute Inc., Cary, North Carolina, USA).

This study was deemed research-exempt by the NYC DOHMH Institutional Review Board.

\section{RESULTS}

During the study period, there were 19677 admissions to NYC jails among 12078 unique women. Of 12078 women, 10828 $(89.7 \%)$ received medical intake; the remainder were released from jail prior to intake. Median age was 35 (range: 
16-78) years. Mean number of incarcerations per woman was 1.6 (range: 1-18). Median cumulative LOS was 16 (range: 0-819) days. The majority of women were non-Hispanic Black (59.2\%) and Hispanic (26.0\%). Women self-reported homelessness $(7.3 \%)$, current drug use $(40.7 \%)$, and lifetime physical assault (23.1\%), sexual abuse (17.5\%), and IPV (14.4\%). Over $25 \%$ were previously incarcerated in NYC jails. Women reported multiple current sex partners (9.1\%); only $30.8 \%$ reported condom use with current partners. Seven hundred $(6.5 \%)$ women were defined as FSW; mean incarcerations per FSW was 2.97 (range: 1-18).

Of 10828 women, 10115 (93.4\%) received 15950 tests for $\mathrm{Ct}$ and $\mathrm{Ng}$ prior to jail release. Of 10115 women, $723(7.1 \%)$ had $\geq 1$ STI: Ct $6.2 \%(\mathrm{n}=623 ; 95 \%$ CI $5.7 \%$ to $6.7 \%) ; \mathrm{Ng}$ $1.7 \%(\mathrm{n}=167 ; 95 \%$ CI $1.4 \%$ to $1.9 \%)$; both $67(0.66 \%)$. Of 723 women, $478(66.1 \%)$ were treated with antimicrobials prior to jail release. Fourteen percent (103/723) of all Ct and $\mathrm{Ng}$ were among FSW; of these, 76\% (78/103) were treated in jail. Of 10828 women, 975 (9.0\%) had HIV infection; the majority were identified by self-report $(n=923)$ and EHR documentation of prior infection $(n=25)$. In addition, $6612(61.1 \%)$ women were HIV-tested in jail; 27 (0.4\%) tested positive. Among FSW, 76 (10.9\%) had HIV infection, with 67 (88.2\%) identified by self-report. Of 10828 women, 1525 (14.1\%) had $\mathrm{Ct}, \mathrm{Ng}$ or HIV infection; 114 (1.1\%) had two, and 4 (0.04\%) had all three infections.

FSW status was associated with all descriptive variables in table 1 in bivariate analysis $(p<0.05)$ except race/ethnicity $(p=0.96)$, which was retained in multivariate analysis for studylevel interest. In multivariate analysis, Ct (AOR: 1.55; 95\% CI 1.17 to $2.05 ; \mathrm{p}<0.0001)$, but not $\mathrm{Ng}$ or $\mathrm{HIV}$ infection, remained associated with FSW status, as did age 20-24 years, residing in boroughs other than Manhattan, $\geq 6$ prior incarcerations, $\geq 2$ incarcerations during study period, condom use with current sex partners, multiple sex partners and current drug use (table 1). FSW status was less likely with age $\geq 55$ years, ever homelessness, married/cohabiting status and >high school education.

\section{DISCUSSION}

This is the first study to examine STI prevalence among FSW in NYC jails. We found many women had Ct, particularly FSW, consistent with published reports. ${ }^{6-9}$ FSW were more likely to be age 20-24 years, the age often at highest Ct risk. ${ }^{3}$ While the association between FSW and increased STI rates is not new, the high $\mathrm{Ct}$ prevalence detected among FSW in our study merits further attention. Nearly $25 \%$ of STI-positive FSW were released from jail prior to treatment, increasing risk of STI sequelae and transmission to sex partners. Similarly, though HIV infection was not independently associated with FSW status in our study, the high positivity (10.9\%) among FSW is concerning. FSW often lack access to needed clinical and social services, making jail-based and community-based interventions imperative. $^{458}$

As expected, FSW status was associated with multiple sex partners; $>20 \%$ of FSW reported $\geq 2$ current partners. FSW status was also associated with recidivism before and during the study period, reflecting the social instability experienced by many FSW. FSW also reported violent histories, with $\geq 20 \%$ reporting sexual abuse, physical assault or IPV. FSW often experience gender-based violence, which is associated with $\mathrm{Ct}$ STI. ${ }^{10}$ Lack of safe work venues may endanger women by creating access barriers to condoms, a cornerstone of preventive STI efforts. ${ }^{10}$ We found that FSW status was associated with condom use with current sex partners, perhaps reflecting that NYC DOHMH sex worker outreach and free condom provision is working; however, only $50 \%$ of FSW reported using condoms. Inconsistent condom use by FSW has been previously reported. ${ }^{9}{ }^{10}$ Sexual violence by clients is a noted barrier to condom negotiation. Threats of imminent violence create difficulties in negotiating safe sex practices, increasing HIV and STI risk. Women who are substance-addicted may be at higher risk for violence. ${ }^{10}$ The majority $(57.6 \%)$ of FSW in our study reported current drug use. The observed relationships between violence exposure, condom use and STI risk among FSW warrant further study, as do the findings that FSW were more likely to reside outside of Manhattan and less likely to report homelessness.

Our study has limitations. Our FSW definition may underestimate the true prevalence as women engaging in sex work may not be charged with prostitution. However, currently, jail clinicians do not inquire about sex work; as such, prostitution criminal charges are the only proxy available for defining FSW. Another limitation is that many descriptive variables were selfreported and subject to recall and social desirability bias. Finally, our study was conducted in a large urban jail; thus, findings may not be generalisable to FSW in other settings.

We found that incarcerated FSW were at higher risk for $\mathrm{Ct}$ than non-FSW incarcerated women in NYC jails. FSW with multiple sex partners, inconsistent condom use, and lack of community-based health care access may be at increased risk for STI sequelae and transmission. ${ }^{4}$ Prevention interventions including peer outreach services, HIV counselling and testing, harm reduction education, and STI testing and management are associated with declines in HIV and STI prevalence among FSW. ${ }^{8}$ In NYC jails, our study findings are being used to design similar targeted interventions to identify FSW, provide clinical and preventive services in jail, and coordinate care with community partners. Interventions will be designed to address not only the medical, but also mental health and social services needs of this medically vulnerable population. ${ }^{4} 8$

\section{Key messages}

- Sexually transmitted infections (STI) are an important cause of morbidity among correctional populations in the USA.

- Incarcerated women, particularly female sex workers (FSW), are at high risk for STI and report sexual behaviours such as unprotected sex, sex for drugs or money or multiple sex partners.

- FSWs incarcerated in New York City (NYC) jails were at higher risk for chlamydia STI than non-FSW incarcerated women.

\section{Handling editor David Gurnham.}

Contributors FP, MK, HA and HV designed the study. FP, MK, HA and RL collected and analysed the data. All authors contributed to writing and revising the manuscript.

Disclaimer The findings and conclusions in this paper are those of the authors and do not necessarily represent the views of the Centers for Disease Control and Prevention.

\section{Competing interests None.}

Provenance and peer review Not commissioned; externally peer reviewed.

Open Access This is an Open Access article distributed in accordance with the Creative Commons Attribution Non Commercial (CC BY-NC 3.0) license, which 
permits others to distribute, remix, adapt, build upon this work non-commercially, and license their derivative works on different terms, provided the original work is properly cited and the use is non-commercial. See: http://creativecommons.org/ licenses/by-nc/3.0/

\section{REFERENCES}

1 Franklin W, Katyal M, Mahajan R, et al. Chlamydia and gonorrhea screening using urine -based nucleic acid amplification testing among males entering New York City jails: a pilot study. J Correct Health Care 2012;18:120-30.

2 Willers D, Piepert J, Allsworth J, et al. Prevalence and predictors of sexually transmitted infection among newly incarcerated females. Sex Transm Dis 2008:35:68-72.

3 Joesoef RM, Weinstock HS, Kent CK, et al. \& the Corrections STD Prevalence Monitoring Group. Sex and age correlates of chlamydia prevalence in adolescents and adults entering correctional facilities, 2005: implications for screening policy. Sex Trans Dis 2009;36:S67-71.

4 Murphy AK, Venkatesh SA. Vice careers: the changing contours of sex work in New York City. Qual Sociol 2006;29:129-54.
5 Lee J, Vlahov D, Freudenberg N. Primary care and health insurance among women released from New York City Jails. J Health Care Poor Underserved 2006;17:200-17.

6 Parvez FM, Tang ALF, Blank S. Sexually transmitted infections in correctional settings. In: Zenilman J, Shahmanesh M, eds. Sexually transmitted infections: diagnosis, management, and treatment . Massachusetts, USA: Jones \& Bartlett Learning, LLC, 2012.

7 Mertz K, Schwebke J, Gavdos C, et al. Screening women in jails for chlamydial and gonococcal infection using urine tests: feasibility, acceptability, prevalence, and treatment rates. Sex Transm Dis 2002;29:271-6.

8 Steen R, Dallabetta G. Sexually transmitted infection control with sex workers: regular screening and presumptive treatment augment efforts to reduce risk and vulnerability. Reprod Health Matters 2003;11:74-90.

9 Pitpitan EV, Kalichman SC, Eaton LA, et al. HIV/STI risk among venue-based female sex workers across the globe: a look back and the way forward. Curr HIVIAIDS Rep 2013; 10:65-78

10 Salazar LF, Crosby RA, Diclemente RJ. Exploring the mediating mechanism between gender-based violence and biologically confirmed Chlamydia among detained adolescent girls. Violence Against Women 2009;15:258-75. 